\title{
The Future Evolution of the U.S. Health Care Entitlement System
}

\section{Randall D*}

American Research and Policy Institute Suite, NW, Washington, USA

US health spending continues to grow as a percentage of the gross domestic product and there is no sign that this trend will stop even with a change of presidential Administration. The Affordable Care Act (ACA) will continue to be the dominant health policy tool that addresses both coverage and cost issues. While the public views the ACA as a major change it is in reality an incremental policy shift of past policy choices in private insurance market regulation and state-based Medicaid systems.

The future of US health care policy, I argue, is more of the same incremental policy advance as we have seen in the past. The US Congress is very unlikely to repeal the ACA and much more likely to make changes that address coverage and identified implementation flaws. I suggest that we are most likely to see more states abandon their state health insurance exchanges and opt for the federal exchange, thus further institutionalizing the ACA system and further federal control of health insurance markets. States are also likely to continue to enroll more beneficiaries in Medicaid also further cementing the importance of the program in a federal scheme of health care coverage.

In addition to further incremental ACA policy change, I also suggest that fraud prevention and mitigation are also likely to play a more important role as noted in previously published research [1]. Additionally, I argue that the study of demand for health care services from beneficiaries and how market participants induce health care demand should be further studied in the context of the future evolution of all health care entitlements. As researchers and policy practitioners begin to explore future policy changes in the US entitlement state, they should consider the impact of changes on not only costs but also beneficiary health and well-being. The research outlined can assist in informing political leaders about what policy choices are best for the citizenry.

\section{Reference}

1. Parente ST, Oberlin S, Tomai L, Randall D (2016) The potential savings of using predictive analytics to staunch medicaid fraud. Journal of Health and Medical Economics 2: 2 .
*Corresponding author: David Randall, American Research and Policy Institute, Suite 2001250 Connecticut Avenue, NW, Washington, DC 20036, USA, E-mail: info@arapi.org

Received October 18, 2016; Accepted October 19, 2016; Published October 26 2016

Citation: Randall D (2016) The Future Evolution of the U.S. Health Care Entitlement System. Health Care Current Reviews 4: e104. doi: 10.4172/2375-4273.1000e104

Copyright: ( 2016 Randall D. This is an open-access article distributed under the terms of the Creative Commons Attribution License, which permits unrestricted use, distribution, and reproduction in any medium, provided the original author and source are credited. 